\title{
Rekomendasi Inovasi Adaptasi di Tengah Pandemi Berdasarkan Strategi Pemasaran: Studi Kasus Usaha Kuliner Warung Halal
}

\author{
Elanjati Worldailmi \\ Teknik Industri Universitas Islam Indonesia \\ Jalan Kaliurang KM 14,5 Sleman, DI Yogyakarta, Indonesia \\ Email: elanjati.worldailmi@uii.ac.id
}

\begin{abstract}
ABSTRAK
Dengan adanya pandemi Covid 19, banyak usaha yang terkena imbasnya. Pelaku usaha perlu segera beradaptasi agar tetap bertahan, tak terkecuali usaha kuliner. Warung Halal merupakan salah satu usaha kuliner yang hidup di era pandemi. Warung Halal telah melakukan beberapa evaluasi, seperti evaluasi pada waktu tunggu pemesanan, asap bakaran sate yang masuk ke ruangan dan membuat aroma pakaian pelanggan berbau bakaran, banyaknya usaha sejenis di sekitar lokasi, serta varian menu yang ingin diperbanyak. Penelitian dan pengabdian masyarakat ini dilakukan untuk memberikan usulan solusi bagi evaluasi yang sudah ada. Jenis penelitian ini bersifat deskriptif kualitatif. Dalam penelitian ini difokuskan pada strategi adaptasi dari tantangan atau permasalahan yang diperoleh yang kemudian dilanjutkan dengan usulan solusi terhadap tantangan atau permasalahan tersebut. Teknik yang digunakan dalam penelitian ini adalah observasi, wawancara, serta studi literatur. Usulan terkait evaluasi dari hasil wawancara dan observasi antara lain: menambah dua orang tenaga kerja pada setiap shift, mengubah posisi pembakaran sate atau memindahkan lokasi pembakaran sate, melakukan segmentasi pasar dan diferensiasi produk (mem-breakdown sasaran konsumen yang hendak dituju serta mengemas Warung Halal menjadi tempat yang menarik bagi pelanggan dengan memanfaatkan lahan parkir untuk spot tempat makan), serta perlu melakukan evaluasi terlebih dahulu terkait varian menu yang telah ada.
\end{abstract}

Kata kunci: kuliner, segmentasi, diferensiasi, strategi

\begin{abstract}
With the COVID-19 pandemic, many businesses have been affected. Business actors need to adapt immediately in order to survive, culinary business is no exception. Warung Halal is one of the culinary businesses that live in the pandemic era. It has carried out several evaluations, such as evaluating the waiting time for orders, the smoke from the grilled satay that enters the room and makes the customer's clothes smell burnt, the number of similar businesses around the location, and the menu variants that you want to increase. This research and community service is carried out to provide proposed solutions for existing evaluations. This type of research is descriptive qualitative. In this study, it is focused on adaptation strategies from the challenges or problems obtained which are then followed by proposed solutions to these challenges or problems. The technique used in this research is observation, interview, and literature study. Proposals related to the evaluation of the results of interviews and observations include: adding two workers in each shift, changing the position of the satay grill or moving the location of the satay grill, segmenting the market and product differentiation (breaking down the target consumers who want to be addressed and packaging Warung Halal into an attractive place for customers by utilizing the parking lot for a place to eat), and it is necessary to conduct an evaluation first regarding the existing menu variants.
\end{abstract}

Keywords: culinary, segmentation, differentiation, strategy 


\section{Pendahuluan}

Terdapat banyak usaha yang terdampak akibat adanya pandemi Covid-19, terutama pada arus kas, bahkan sebagian di antaranya menutup usaha sementara ataupun permanen. Usaha kecil dan menengah merupakan contoh usaha yang merasakan dampaknya dan terpukul akibat pandemi (Rakhmanita, 2021). Pelaku usaha kecil dan menengah harus segera beradaptasi agar tetap dapat bertahan dengan kondisi tersebut. Pengusaha di bidang kuliner merupakan salah satu pihak yang masih bisa bertahan saat pandemi karena kebutuhan pangan merupakan kebutuhan pokok. Walau demikian, nilai omsetnya pun akan berbeda dengan kondisi sebelum pandemi

Bentuk usaha atau bentuk bisnis menurut ukurannya dapat dibedakan menjadi Usaha Mikro, Kecil, Menengah (UMKM) dan Usaha Besar (UB) (Sancoko, 2015). UMKM memiliki pengaruh besar dalam perekonomian Indonesia, bahkan sebanyak 56.534 .592 atau 99,99\% jumlah unit usaha Indonesia adalah UMKM dan sebanyak 107.657.509 penduduk Indonesia merupakan tenaga kerja UMKM (Sancoko, 2015). Hal itu berdampak besar bagi Produk Domestik Bruto (PDB) Indonesia yakni 59,08\% berasal dari UMKM.

Bisnis berupa rumah makan atau restoran merupakan usaha komersial yang dalam pelaksanaannya selalu menghitung untung-rugi dan pada akhirnya mengharapkan keuntungan (Amrullah et al., 2016). Menurut Undang-Undang Nomor 20 Tahun 2008 tentang Usaha Mikro, Kecil, dan Menengah (UMKM), Warung Halal termasuk dalam kategori Usaha Mikro karena merupakan usaha produktif perorangan dan/atau badan usaha perorangan yang memiliki kekayaan bersih di bawah lima puluh juta rupiah tidak termasuk tanah dan bangunan tempat usaha dan/atau memiliki hasil penjualan tahunan tidak lebih dari tiga ratus juta rupiah.

Warung Halal terletak di Jalan Bantul Yogyakarta yang berdiri saat pandemi Covid-19 sudah berlangsung. Warung Halal menyediakan layanan pemesanan online, baik melalui ojek online maupun pengantaran oleh karyawan untuk wilayah di sekitarnya. Gambaran terkait Warung Halal ditunjukkan pada Gambar 1 dan Gambar 2.

Seiring dengan berjalannya waktu, pihak manajemen Warung Halal melakukan evaluasi terhadap usahanya. Rata-rata waktu tunggu pemesanan adalah 30 menit. Jika terdapat antrian pelanggan yang banyak, waktu rata-rata akan semakin lama. Bagi pelanggan yang meluangkan waktu makan saat istirahat kantor, waktu tunggu tersebut tergolong lama. Terdapat keluhan pelanggan terkait asap bakaran sate yang masuk ke dalam ruangan. Selain itu, di kawasan sekitar Warung Halal, terdapat usaha sejenis yang semakin banyak. Sementara, pihak manajemen ingin agar varian menu semakin banyak agar dapat memenuhi berbagai keinginan atau permintaan pelanggan. Evaluasi tersebut kemudian menjadi tantangan bagi manajemen Warung Halal. Agar menjadi pembeda dengan usaha yang lain, Warung Halal ingin membuat suatu perubahan untuk dapat menarik minat pelanggan lebih banyak. Untuk itu dilakukan usulan strategi berupa rekomendasi pembaharuan atau inovasi Warung Halal sebagai bentuk pengabdian masyarakat. 


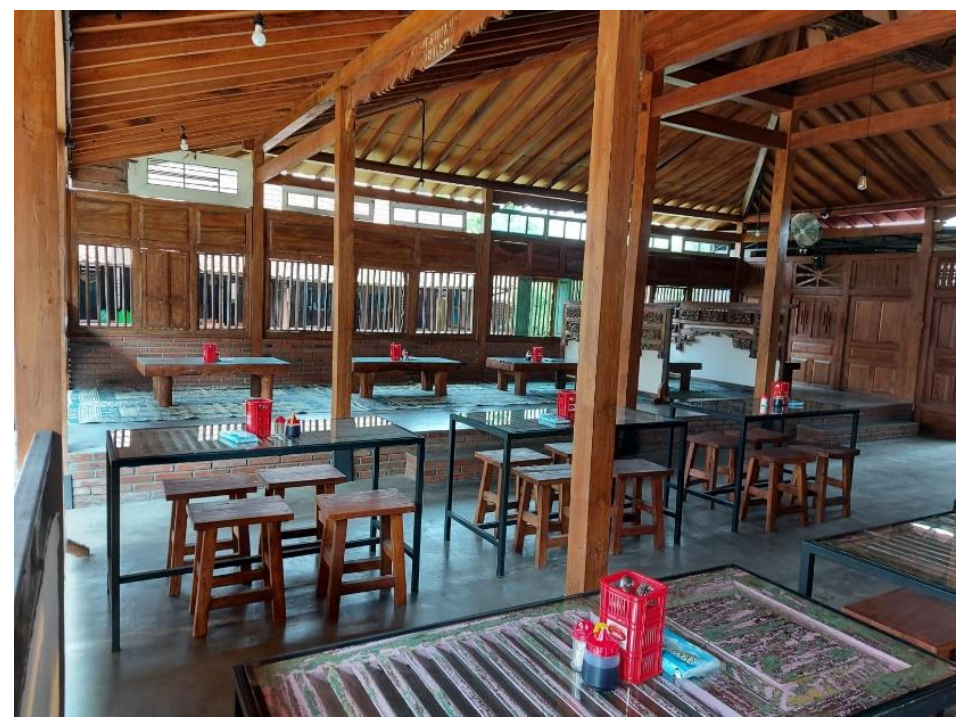

Gambar 1. Kondisi Warung Halal

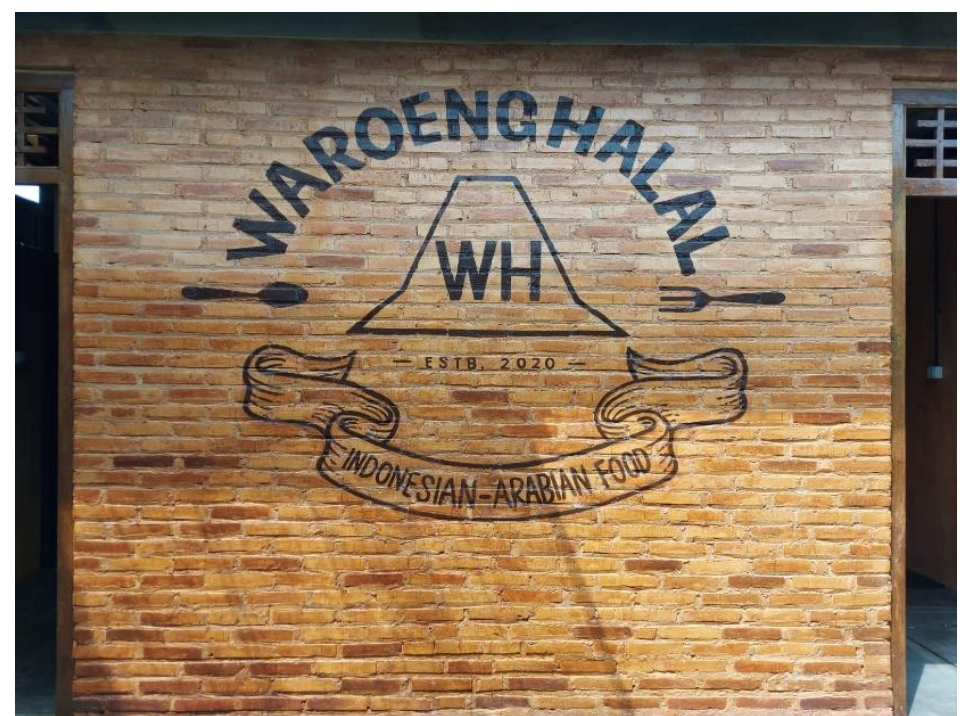

Gambar 2. Spot pada Warung Halal

\section{Tinjauan Pustaka}

Menurut Lupiyoadi (2001) penentuan tingkat kepuasan pelanggan memiliki lima faktor utama yang harus diperhatikan oleh perusahaan, yaitu faktor mutu produk, faktor mutu pelayanan, faktor emosional, faktor harga dan faktor biaya. Sumarwan (2003) mendefinisikan perilaku konsumen sebagai perilaku yang diperlihatkan konsumen untuk mencari, membeli, menggunakan, mengevaluasi dan menghabiskan produk dan jasa yang diharapkan akan memuaskan kebutuhannya. Sementara keputusan melakukan pembelian merupakan hasil dari suatu hubungan yang saling memengaruhi antara faktor-faktor kebudayaan, sosial, pribadi dan psikologi dari pembeli (Kotler, 2005).

Strategi merupakan rencana dalam skala besar dan berorientasi pada masa depan untuk berinteraksi dengan lingkungan yang kompetitif sehingga perusahaan dapat mencapai tujuannya (Pearce dan Robinson, 2007). Porter (1985) membagi tiga strategi generik menjadi kepemimpinan biaya (cost leadership strategy), diferensiasi (differentiation strategy), dan fokus pada segmen pasar tertentu (focus strategy).

Menurut Safitri dkk (2018), dalam pengembangan usaha kuliner, terdapat beberapa strategi yang harus dilakukan, yaitu: menjalin hubungan yang baik antara pemilik usaha dengan penyedia bahan baku harus berjalan dengan baik guna terpenuhinya kebutuhan bahan baku yang mendukung 
terlaksananya proses produksi, menjalin hubungan yang baik harus antara pemilik usaha dengan tenaga kerja, serta strategi dalam menjaga kualitas produk

Untuk dapat menerapkan strategi dan melakukan pengembangan bisnis, dibutuhkan peran manajemen. Manajemen merupakan cara yang perlu dilakukan untuk dapat mengatur, membimbing, dan memimpin dengan perantara orang lain untuk dapat mencapai tujuan yang telah ditetapkan (Daryanto dan Abdullah, 2013). Fokus manajemen strategis adalah integrasi dari manajemen, pemasaran, keuangan, produksi dan operasional, research and development, dan sistem informasi untuk mencapai kesuksesan (Sancoko, 2015).

Manajemen stratejik merupakan sekumpulan keputusan dan tindakan untuk diperoleh formulasi dan implementasi rencana yang dibuat agar tujuan perusahaan tercapai (Pearce dan Robinson, 2007). Umar (2002) menyimpulkan enam aspek yang perlu dibahas dalam sebuah rencana bisnis atau business plan, yakni aspek teknis, aspek pasar, aspek legal, aspek manajemen, aspek ekonomi dan lingkungan, dan aspek finansial. Dalam rencana bisnis terdapat empat hal utama yang harus ada, yaitu rencana strategis bisnis, pemasaran, keuangan, dan operasional (Rangkuti, 2013).

\section{Metodologi Penelitian}

Jenis penelitian ini bersifat deskriptif kualitatif. Penelitian deskriptif kualitatif adalah suatu metode yang digunakan untuk mendeskripsikan suatu hasil penelitian tetapi tidak digunakan untuk membuat kesimpulan yang lebih luas (Sugiono, 2009). Penelitian kualitatif digunakan untuk lebih memahami dan menangkap fenomena sosial dari persepsi informan. Dalam penelitian ini difokuskan pada strategi adaptasi dari tantangan atau permasalahan yang diperoleh yang kemudian dilanjutkan dengan usulan solusi terhadap tantangan atau permasalahan tersebut.

Teknik yang digunakan dalam penelitian ini adalah observasi dan wawancara untuk mengidentifikasi permasalahan yang ada dengan pihak manajemen serta studi literatur untuk dapat memberikan usulan penyelesaian permasalahan. Sumber data yang diperoleh adalah data primer yang berasal dari wawancara serta data sekunder dari pihak manajemen. Penelitian dilakukan pada Rumah Makan Warung Halal yang berlokasi di Jalan Bantul Yogyakarta. Tahapan penelitian pengabdian masyarakat yang dilakukan yaitu observasi dan wawancara awal terkait permasalahan, studi literatur terkait topik riset, wawancara dan diskusi lanjutan terkait ide usulan, pengumpulan data sekunder, kemudian dilanjutkan penyampaian usulan atau rekomendasi sebagai perbaikan atau solusi terkait permasalahan.

\section{Hasil dan Pembahasan}

Sebagai bentuk pengabdian masyarakat, Warung Halal sebagai salah satu UMKM kuliner berbentuk rumah makan atau restoran menjadi objek pada penelitian ini. Dari hasil wawancara dengan pihak pemilik dan manajemen, berdasarkan evaluasi yang telah dilakukan, diperoleh beberapa evaluasi sebagai berikut:

a. Waktu tunggu pemesanan yang tergolong lama

b. Asap bakaran yang mengenai pelanggan sehingga pakaian pelanggan berbau asap

c. Usaha sejenis di sekitar lokasi

d. Varian menu yang ingin diperbanyak

Berdasarkan evaluasi tersebut, kemudian dilakukan usulan solusi permasalahan sebagai bahan untuk pertimbangan terkait strategi dalam mengembangkan usaha melalui rencana bisnis. Strategi merupakan media perusahaan untuk mencapai tujuan dengan berorientasi pada masa depan untuk berinteraksi dengan lingkungan yang kompetitif (Pearce dan Robinson, 2007). Beberapa strategi menurut Porter (1985) adalah adanya diferensiasi serta fokus pada segmen pasar tertentu. Selain itu, menjaga kualitas produk merupakan salah satu strategi penting untuk mengembangkan usaha kuliner (Safitri dkk, 2018). 


\subsection{Waktu Tunggu}

Dari data penelitian diperoleh daftar nama pegawai beserta bagian/posisi kerjanya yang ditunjukkan pada Tabel 1. Aktivitas harian dibagi menjadi dua shift, yaitu pukul 9.00 sampai dengan 15.00 serta pukul 15.00 sampai dengan 2100. Setiap shift berisi dua orang yang terdiri dari cheff serta waiters dan chasier. Adapaun manager secara fleksibel datang untuk memenej dan mengontrol rumah makan. Dari hasil wawancara dan observasi, waktu tunggu pemesanan yang tergolong lama dicari penyebabnya dan diperoleh hasil sebagai berikut:

- Keterbatasan kemampuan cheff untuk memasak secara parallel dikarenakan keterbatasan jumlah sumber daya manusia.

- Tugas waiter yang mempersiapkan nasi, minuman, dan mengantarkan kepada pelanggan terkadang bersamaan dengan waktu pelanggan lain untuk membayar.

- Waiter juga membutuhkan waktu untuk mencuci peralatan serta membereskan dan membersihkan meja pelanggan yang telah kosong.

- Peramalan/forcasting terhadap kebutuhan bahan mentah (termasuk daging) yang belum optimal.

- Bersamaan dengan aktivitas pelayanan pemesanan aqiqah.

Dari beberapa penyebab tersebut kemudian diusulkan solusi yang mungkin dapat dilakukan sebagai pertimbangan pengambilan keputusan. Usulan terhadap penyebab lamanya waktu tunggu pemesanan ditampilkan pada Tabel 2. Dari Tabel 2, salah satu hal yang penting adalah usulan penambahan tenaga kerja, yaitu cheff atau cheff helper serta tambahan tenaga kerja untuk membagi pekerjaan antara waiter dan chasier. Maka, usulan yang dilakukan adalah menambah dua orang tenaga kerja pada setiap shift. Dengan adanya usulan tersebut, usulan pembagian tugas/pekerjaan ditampilkan pada Tabel 3.

Tabel 1. Data Pegawai dan Deskripsi Kerjanya

\begin{tabular}{|c|c|c|c|}
\hline No & Inisial Nama Pegawai & Posisi & Deskripsi \\
\hline 1 & MMNF & Owner & Pemilik usaha, mengarahkan dan memimpin \\
\hline 2 & ST & Manager & $\begin{array}{l}\text { Memenej operasional sehari-hari (termasuk } \\
\text { memenej kebutuhan daging dan bahan mentah } \\
\text { lainnya) }\end{array}$ \\
\hline 3 & $\mathrm{AW}$ & Head Cheff & $\begin{array}{l}\text { Bertanggung jawab pada masakan serta bumbu } \\
\text { standarnya }\end{array}$ \\
\hline 4 & WAP & Cheff & Bertanggung jawab pada masakan \\
\hline 5 & IW & Waiter \& Chasier & $\begin{array}{l}\text { Menyiapkan minum, nasi, dan mengantarkan } \\
\text { kepada pelanggan, mencuci perlengkapan, serta } \\
\text { melakukan transaksi pembayaran dengan pelanggan }\end{array}$ \\
\hline 6 & INR & Waiter \& Chasier & $\begin{array}{l}\text { Menyiapkan minum, nasi, dan mengantarkan } \\
\text { kepada pelanggan, mencuci perlengkapan, serta } \\
\text { melakukan transaksi pembayaran dengan pelanggan }\end{array}$ \\
\hline
\end{tabular}

Tabel 2. Usulan Solusi untuk Mempercepat Waktu Tunggu

\begin{tabular}{|c|c|c|c|}
\hline \multirow{3}{*}{$\begin{array}{c}\text { No } \\
1\end{array}$} & Penyebab & Usulan Solusi & Konsekuensi Usulan Solusi \\
\hline & $\begin{array}{l}\text { Keterbatasan kemampuan cheff } \\
\text { untuk memasak secara parallel } \\
\text { dikarenakan keterbatasan } \\
\text { jumlah sumber daya manusia. }\end{array}$ & $\begin{array}{l}\text { Sebelum rumah makan dibuka, } \\
\text { cheff sudah mempersiapkan } \\
\text { bahan-bahan mentah yang } \\
\text { ditempatkan di area yang mudah } \\
\text { dijangkau }\end{array}$ & $\begin{array}{l}\text { Membutuhkan waktu } \\
\text { persiapan yang lebih lama bagi } \\
\text { cheff (menambah waktu } \\
\text { lembur). }\end{array}$ \\
\hline & & Menambah tenaga kerja (cheff). & $\begin{array}{l}\text { Menambah pengeluaran untuk } \\
\text { membayar tambahan cheff }\end{array}$ \\
\hline 2 & $\begin{array}{l}\text { Tugas waiter yang } \\
\text { mempersiapkan nasi, }\end{array}$ & $\begin{array}{l}\text { Menambah tenaga kerja } \\
\text { sehingga pembagian tugas }\end{array}$ & $\begin{array}{l}\text { Menambah pengeluaran untuk } \\
\text { membayar tambahan tenaga }\end{array}$ \\
\hline
\end{tabular}




\begin{tabular}{|c|c|c|c|}
\hline No & Penyebab & Usulan Solusi & Konsekuensi Usulan Solusi \\
\hline & $\begin{array}{l}\text { minuman, dan mengantarkan } \\
\text { kepada pelanggan terkadang } \\
\text { bersamaan dengan waktu } \\
\text { pelanggan lain untuk } \\
\text { membayar. }\end{array}$ & $\begin{array}{l}\text { sebagai waiter dan chasier lebih } \\
\text { terperinci }\end{array}$ & $\begin{array}{l}\text { kerja (waiter dan cashier } \\
\text { dipisah) }\end{array}$ \\
\hline 3 & $\begin{array}{l}\text { Waiter juga membutuhkan } \\
\text { waktu untuk mencuci peralatan } \\
\text { serta membereskan dan } \\
\text { membersihkan meja pelanggan } \\
\text { yang telah kosong. }\end{array}$ & $\begin{array}{l}\text { Menambah perlengkapan makan } \\
\text { dan minum agar tidak sampai } \\
\text { kehabisan jika belum sempat } \\
\text { untuk dicuci }\end{array}$ & $\begin{array}{l}\text { Menambah pengeluaran untuk } \\
\text { pengadaan tambahan } \\
\text { perlengkapan. Jumlah } \\
\text { penambahan perlengkapan } \\
\text { disesuaikan dengan kebutuhan } \\
\text { berdasar peramalan penjualan. }\end{array}$ \\
\hline 4 & $\begin{array}{l}\text { Peramalan/forcasting terhadap } \\
\text { kebutuhan bahan mentah } \\
\text { (termasuk daging) yang belum } \\
\text { optimal. }\end{array}$ & $\begin{array}{l}\text { Mempelajari dan melakukan } \\
\text { peramalan kebutuhan bahan } \\
\text { berdasarkan rekapitulasi } \\
\text { penjualan }\end{array}$ & $\begin{array}{l}\text { Menjadi tanggung jawab } \\
\text { manajer. Manajer perlu } \\
\text { mengolah data dari rekap } \\
\text { penjualan. }\end{array}$ \\
\hline 5 & $\begin{array}{l}\text { Bersamaan dengan aktivitas } \\
\text { pelayanan pemesanan aqiqah }\end{array}$ & $\begin{array}{l}\text { Mensubkontrakkan pekerjaan } \\
\text { yang bukan utama serta } \\
\text { menambah tenaga kerja lepas } \\
\text { pada saat pemesanan aqiqah. }\end{array}$ & $\begin{array}{l}\text { Membayar biaya overtime } \\
\text { kepada tenaga lepas. }\end{array}$ \\
\hline
\end{tabular}

Tabel 3. Usulan Pembagian Tugas Setiap Shift

\begin{tabular}{cll}
\hline No & \multicolumn{1}{c}{ Posisi } & \multicolumn{1}{c}{ Deskripsi Kerja } \\
\hline 1 & Cheff & Bertanggung jawab pada masakan \\
2 & Cheff Helper & Membantu cheff; mempersiapkan nasi dan minum yang dipesan \\
3 & Chasier & Fokus pada pembayaran \\
4 & Waiter & $\begin{array}{l}\text { Mengantarkan kepada pelanggan, membersihkan meja pelanggan, dan mencuci } \\
\text { perlengkapan }\end{array}$ \\
\hline
\end{tabular}

Jika tugas waiter terpisah untuk mengantarkan kepada pelanggan, membersihkan meja pelanggan, serta mencuci perlengkapan, pengadaan penambahan perlengkapan dapat dikurangi. Waiter dapat fokus terhadap pelayanan kepada pelanggan secara langsung. Sementara untuk persiapan penyajian makanan dibantu oleh cheff helper. Namun, perlu dipertimbangkan batasan biaya operasional untuk penggajian. Apakah signifikan untuk melakukan penambahan pegawai atau tidak. Riset pengabdian masyarakat ini akan dibahas lebih lanjut dengan pihak internal terkait usulan solusi terkait penambahan sumber daya. Hal tersebut juga disesuaikan dengan kapasitas dan jumlah pelanggan yang biasa hadir per harinya. Untuk itu, data penjualan perlu dipelajari lebih lanjut sebagai dasar pengambilan keputusan.

Tabel 4. Usulan Solusi Penanganan Asap Bakaran Sate

\begin{tabular}{|c|c|c|}
\hline No & Usulan & Konsekuensi Usulan Solusi \\
\hline 1 & Penambahan exhaust fan di atas pembakaran sate & $\begin{array}{l}\text { Perlu memperhatikan perawatan dan } \\
\text { maintenance exhaust fan karena material } \\
\text { buangan bakaran sate cenderung besar, } \\
\text { berminyak, dan lengket }\end{array}$ \\
\hline 2 & Mengubah posisi pembakaran sate & $\begin{array}{l}\text { Perlu meninjau ulang signifikansi asap yang } \\
\text { dihasilkan }\end{array}$ \\
\hline 3 & $\begin{array}{l}\text { Memisahkan tempat pembakaran sate dengan } \\
\text { memindahkan lokasinya }\end{array}$ & $\begin{array}{l}\text { Perlu membuat desain dan mempersiapkan } \\
\text { biaya tambahan untuk pembangunan tempat } \\
\text { bakaran sate }\end{array}$ \\
\hline
\end{tabular}


Namun, sebuah perusahaan yang siap untuk berkembang maju membutuhkan pembagian kerja yang terperinci. Hal ini menjadi pertimbangan lain yang perlu ditengok oleh owner dan manager untuk memilih langkah yang tepat. Servis terhadap pelanggan merupakan bagian terpenting pada sebuah perusahaan. Kepuasan pelanggan menjadi hal utama bagi sebuah usaha. Mempercepat waktu tunggu menjadi salah satu servis utama pada perusahaan, khususnya bisnis kuliner.

\subsection{Asap Bakaran}

Asap bakaran merupakan suatu hal yang mengganggu bagi pelanggan. Terlebih jika pelanggan tersebut hendak melakukan aktivitas lain yang resmi (seperti bekerja, menghadiri undangan, dll). Pakain pelanggan akan berbau asap atau makanan yang mengganggu kenyamanan pelanggan di tempat tujuan berikutnya dalam beraktivitas. Dari hasil observasi, asap bakaran yang mengenai pelanggan disebabkan karena tempat pembakaran sate berada satu ruangan (satu lokasi) dengan pelanggan (tidak terpisah), sementara di lokasi tidak terdapat exhaust fan. Selama ini rumah makan tidak menggunakan exhaust fan karena bentuk bangunan rumah makan cenderung terbuka dan harapannya asap pembakaran langsung mengarah keluar. Selain itu, rumah makan sate secara umum jarang menggunakan exhaust fan.

Solusi yang ditawarkan untuk menanggulangi masalah asap bakaran adalah dengan menambahkan exhaust fan di atas tempat pembakaran, mengubah posisi pembakaran sate, atau memisahkan (memindahkan) tempat pembakaran sate. Apabila menggunakan exhaust fan, perawatan dan maintenance perlu diperhatikan karena material buangan pembakaran sate cenderung besar, berminyak, dan lengket (karena manis). Jika melihat lokasi rumah makan yang cukup luas, mengubah posisi atau memisahkan/memindahkan lokasi pembakaran sate dapat dilakukan. Mengubah posisi pembakaran sate dapat diuji coba untuk melihat perubahan kondisi terkait asap bakaran. Jika masih belum signifikan berkurang, memindahkan lokasi pembakaran sate dapat dilakukan. Rangkuman usulan dan konsekuensi usulan solusi ditampilkan pada Tabel 4.

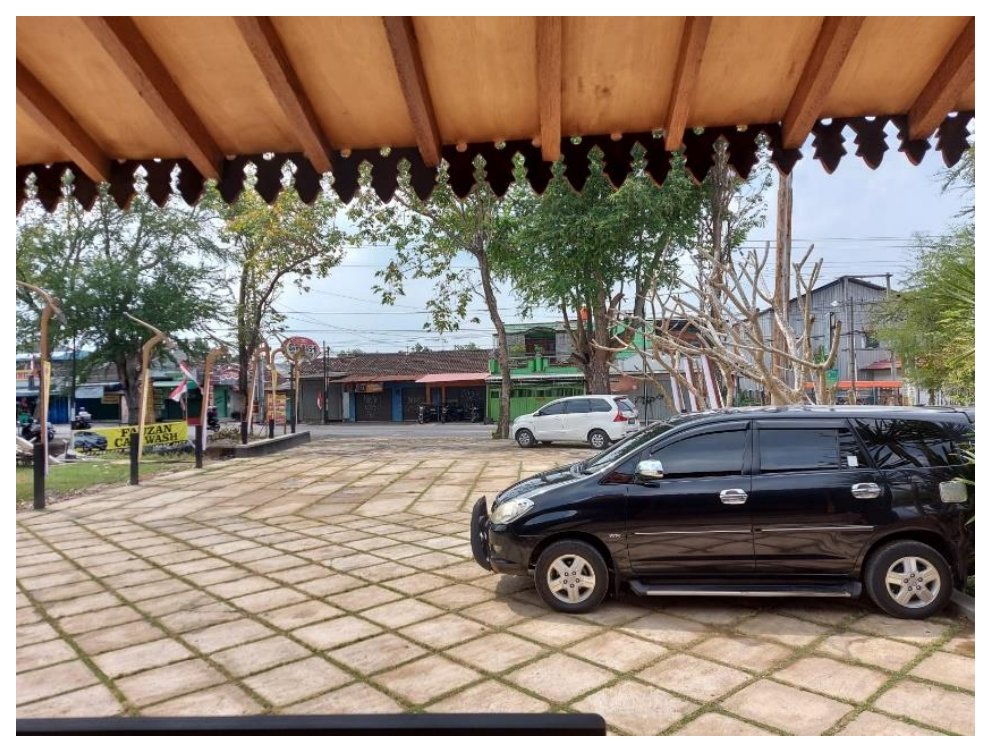

Gambar 3. Halaman Parkir Warung Halal

\subsection{Usaha Sejenis}

Persaingan usaha merupakan suatu hal yang wajar. Dalam menghadapi persaingan, perlu dilakukan perencanaan yang matang bagi sebuah usaha. Strategi bisnis dan pemasaran adalah bagian dari rencana bisnis yang utama dan harus ada, di samping keuangan dan operasional (Rangkuti, 2013). Contoh strategi bisnis dan pemasaran yang dapat dilakukan dalam menghadapi persaingan adalah penentuan segmentasi pasar dan diferensiasi produk. Segmentasi pasar dilakukan agar dapat tepat 
sasaran terhadap segmen pemasaran yang ditujukan. Sementara diferensiasi produk bertujuan untuk membedakan dengan produk lain, misalnya dengan menambahkan add value pada produk tersebut.

Jika melihat dari sisi product, price, place, dan promotion (4P), permasalahan dalam persaingan bisnis ada pada produk yang serupa dengan harga yang hampir sama. Untuk lokasi, Warung Halal memiliki space yang cukup luas, baik untuk parkir, maupun untuk makan. Sementara promosinya masih belum dioptimalkan pada media sosial yang tampak dari kurangnya update postingan pada media sosial.

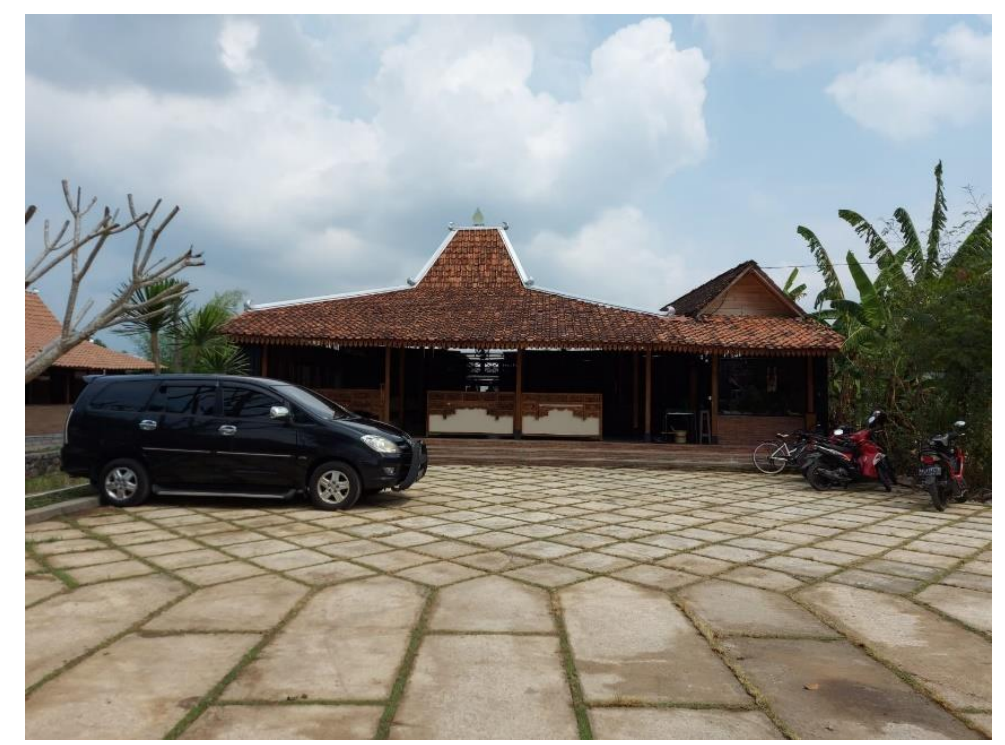

Gambar 4. Halaman Parkir Warung Halal

Warung sate, tongseng, dan gule merupakan produk usaha kuliner yang banyak dan mudah ditemukan, khususnya di wilayah Bantul. Agar menjadi pembeda dengan usaha yang lain serta tepat sasaran pada kelompok konsumen yang dituju, Warung Halal perlu melakukan segmentasi pasar dan diferensiasi produk. Hal tersebut dilakukan guna menjadi unggul terhadap usaha yang sejenis. Pertama-tama pihak manajemen perlu mem-breakdown sasaran konsumen yang hendak dituju. Apakah Warung Halal akan dibawa pada usaha yang sama seperti yang lain, ataukah ada pembedanya.

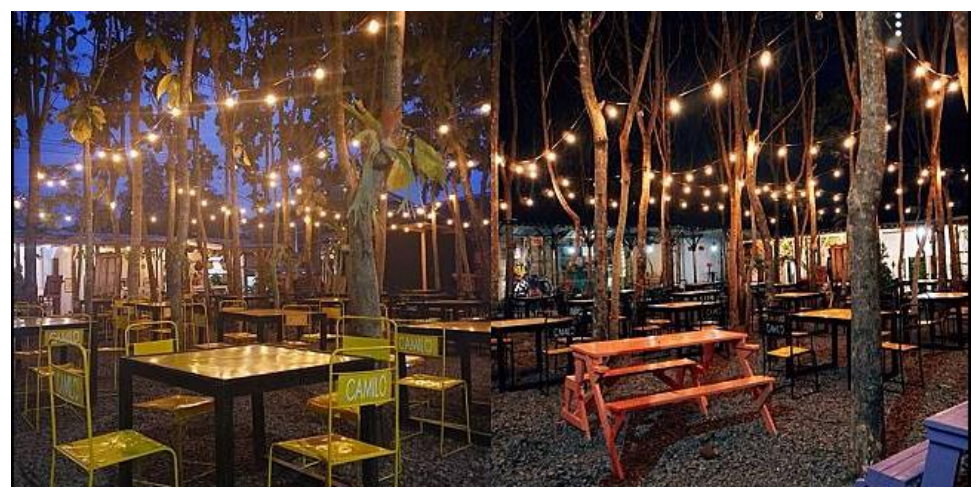

Gambar 5. Referensi Pemanfaatan Halaman Parkir

(Sumber: Wisata Malang, 2019)

Berdasarkan informasi data dan wawancara dengan pihak manajemen, dengan melihat jenis konsumen yang hadir, kelompok konsumen yang hadir bervariasi, antara lain menengah ke atas, rombongan pariwisata, rombongan hobi (sepeda, motor jenis tertentu, dll), jamaah pengajian, serta masyarakat sekitar lokasi. Dengan melihat kawasan usaha beserta lokasi Warung Halal, manajemen 
dapat memanfaatkan area parkir yang luas untuk menambah spot tempat makan yang unik dan menjadi pembeda dengan yang lain. Apalagi jam buka rumah makan adalah sampai dengan malam (pukul 21.00). Spot tempat makan yang diusulkan dapat berada di sebagian halaman parkir dengan menambahkan lampu-lampu kecil (atau lampu hias) di bagian atas, meja kursi yang tahan cuaca, paranet di bagian atas, serta hiasan-hiasan untuk mempercantik. Selain itu, yang dapat membedakan usaha ini dengan yang lain dapat berupa perlengkapan makan dan minum yang unik.

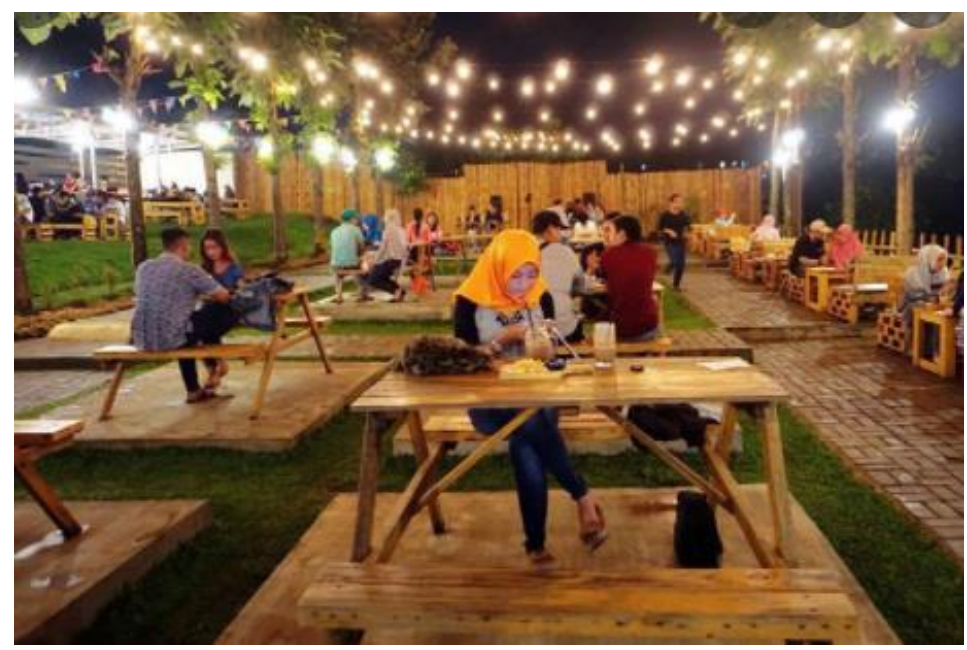

Gambar 6. Referensi Pemanfaatan Halaman Parkir

(Sumber: Trip Canvas: ---)

Halaman dan area parkir Warung Halal ditampilkan pada Gambar 3 dan Gambar 4. Sementara beberapa referensi inspirasi penataan spot makan di luar bangunan ditampilkan pada Gambar 5, Gambar 6, dan Gambar 7.

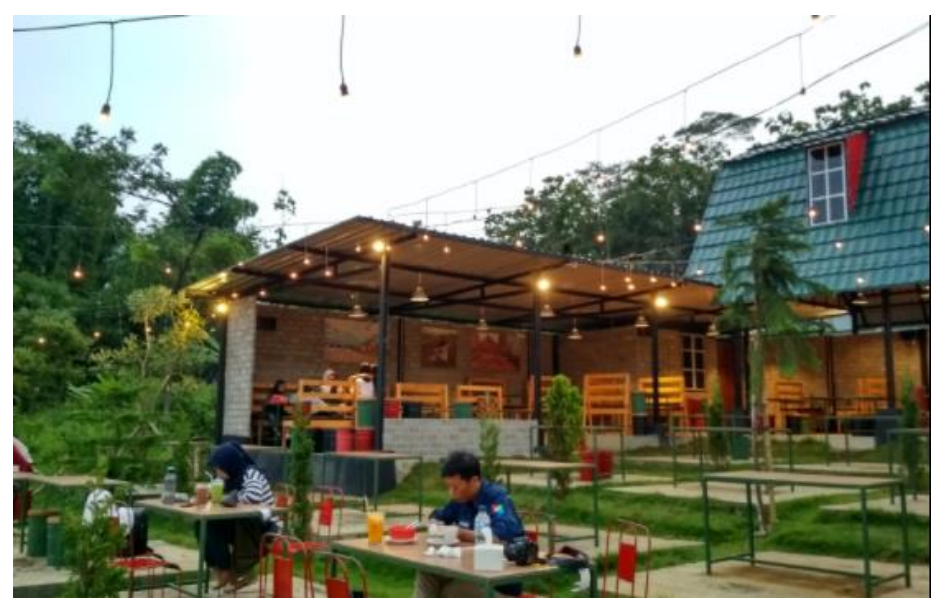

Gambar 7. Referensi Pemanfaatan Halaman Parkir

(Sumber: Arifian, 2018)

\subsection{Varian Menu}

Pihak manajemen menginginkan memperbanyak varian menu untuk melengkapi keinginan dan kebutuhan konsumen. Varian yang diperbanyak merupakan bagian dari diferensiasi produk karena banyaknya usaha sejenis dengan produk yang sama jika melihat kompetitor dari sisi 4P (product, price, place, promotion). Menurut manajemen, varian menu yang banyak dapat menarik minat pengunjung. Namun, perlu dipertimbangkan terkait konsekuensinya. Memperbanyak varian menu mengharuskan cheff memasak lebih banyak jenis serta perlengkapan dan bahan bakunya pun akan 
lebih banyak. Sementara, berdasarkan strategi generic Porter (1985), sebuah usaha perlu untuk fokus pada segmen pasar tertentu dan memiliki diferensiasi. Maka, perlu dipertimbangkan dan dievaluasi lebih lanjut terkait data histori varian menu yang sudah ada. Apakah terdapat varian menu yang kurang diminati, ataukah semua menu diminati. Jika terdapat varian menu yang diminati, bisa diganti dengan varian menu yang mungkin sedang popular pada masanya.

\section{Kesimpulan}

Dari hasil wawancara dengan pihak Warung Halal, evaluasi yang telah dilakukan oleh pihak manajemen antara lain waktu tunggu pemesanan, asap bakaran sate yang masuk ke ruangan dan membuat aroma pakaian pelanggan berbau bakaran, banyaknya usaha sejenis di sekitar lokasi, serta varian menu yang ingin diperbanyak. dari masing-masing tantangan dan evaluasi tersebut kemudian digali lebih dalam untuk dicari usulan dan konsekuensi atas usulan sebagai bahan pertimbangan pihak manajemen untuk mengambil keputusan.

Usulan untuk mempercepat waktu tunggu adalah menambah dua orang tenaga kerja pada setiap shift. Usulan untuk menanggulangi asap bakaran sate yang masuk ke ruangan adalah mengubah posisi pembakaran sate atau memindahkan lokasi pembakaran sate. Mengubah posisi pembakaran sate dapat diuji coba untuk melihat perubahan kondisi terkait asap bakaran. Jika masih belum signifikan berkurang, memindahkan lokasi pembakaran sate dapat dilakukan. Usulan untuk bersaing dengan usaha sejenis adalah dengan melakukan segmentasi pasar dan diferensiasi produk. Pihak manajemen perlu mem-breakdown sasaran konsumen yang hendak dituju serta mengemas Warung Halal menjadi tempat yang menarik bagi pelanggan dengan memanfaatkan lahan parkir untuk spot tempat makan. Sedangkan usulan untuk menambah varian menu adalah perlu melakukan evaluasi terlebih dahulu terkait varian menu yang telah ada.

\section{Daftar Pustaka}

Amrullah, Hubeis, M., dan Palupu, N.S. (2016) Strategi Pengembangan Bisnis Restoran Makasar Berbahan Baku Hasil Ternak dalam Mendukung Penyediaan Makanan Sehat. Jurnal Manajemen IKM Volume 11 Nomor 1, Februari 2016 (1-9).

Arifian, F. 2018. Rasakan Sensasi Cafe Outdoor Di Ling Ling Green Barn Eatery. https://www.feryarifian.com/2018/01/linglinggreenbarn.html.

Daryanto \& Abdullah. (2013). Pengantar Ilmu Manajemen dan Komunikasi. Jakarta: Prestasi Pustaka Raya.

Kotler, P. 2005. Manajemen Pemasaran. Alih Bahasa Benyamin Mohan. Edisi 11, Jilid 1. PT. Intan Sejati Klaten, Jakarta.

Lupiyoadi, R. 2001. Manajemen Pemasaran Jasa Teori dan Praktek. Salemba Empat, Jakarta.

Pearce, J., \& Robinson, R. (2007). Formulation, Implementation, and Control of Competitive Strategy. NY: McGraw-Hill.

Rakhmanita, A. (2021) Usaha Kuliner Berskala Mikro dan Kecil di Desa Gunung Sindur Kabupaten Bogor: Kondisi Pasca Covid-19. Perspektif: Jurnal Ekonomi \& Manajemen Universitas Bina Sarana Informatika Volume 19 No 1 Maret 2021.

Rangkuti, F. (2003). Business Plan. PT. Gramedia Pustaka Utama, Jakarta.

Safitri, I., Salman, D., dan Rahmadanih. (2018). Strategi Pengembangan Usaha Kuliner: Studi Kasus Warung Lemang di Jeneponto, Sulawesi Selatan. Jurnal Sosual Ekonomi Pertanian Vol 14 No 2 Juni 2018.

Sancoko, A.H. (2015) Strategi Pengembangan Bisnis Usaha Makanan dan Minuman pada Depot Time to Eat Surabaya. AGORA Vol 3 No 1 (2015).

Sugiono. (2009). Metode Penelitian Kuantitatif. Bayu Indra Grafika.

Sumarwan, U. 2003. Prilaku Konsumen. Teori dan Penerapannya dalam Pemasaran. Ghalia Indonesia, Jakarta. 
Trip Canvas. ---. 26 Cafe/Restoran Unik di Malang yang Hits, Instagramable dan Terbaru. https://indonesia.tripcanvas.co/id/malang/cafe-restoran-unik-di-malang/

Umar, H. (2002). Studi Kelayakan Bisnis. Jakarta: Gramedia Pustaka Utama.

Wisata Malang, 2019. Cafe Alam, Camilo Colours and Garden Café. https://www.wisatamalangku.com/2019/06/cafe-alam-camilo-colours-and-garden-cafe.html. 